\title{
A Non-Pt Catalyst for Improved Oxygen Reduction Reaction in Microbial Fuel Cells
}

\author{
Jy-Yeon Kim, Sang-Beom Han, Sang-Eun $\mathrm{Oh}^{\dagger}{ }^{\dagger}$, and Kyung-Won Park* \\ Department of Chemical and Environmental Engineering, Soongsil University, Seoul 156-743, Republic of Korea \\ ${ }^{\dagger}$ Department of Biological Environment, Kangwon National University, Chuncheon, Kangwon-do, Republic of Korea
}

(Received November 26, 2010 : Accepted January 26, 2011)

\begin{abstract}
Fe-tetramethoxyphenylporphyrin on carbon black (Fe-TMPP/C) is examined and compared with carbon $(\mathrm{C})$ and $\mathrm{Pt}$-coated carbon $(\mathrm{Pt} / \mathrm{C})$ for oxygen reduction reaction in a two chambered microbial fuel cell (MFC). The Fe-TMPP/C is prepared by heat treatment and characterized using SEM, TEM, and XPS. The electrochemical properties of catalysts are characterized by voltammerty and single cell measurements. It is found that the power generation in the MFC with Fe-TMPP/C as the cathode is higher than that with $\mathrm{Pt} / \mathrm{C}$. The maximum power of the Fe-TMPP/C is $0.12 \mathrm{~mW}$ compared with $0.10 \mathrm{~mW}(\mathrm{Pt} / \mathrm{C})$ and $0.02 \mathrm{~mW}(\mathrm{C})$. This high output with the Fe-TMPP/C indicates that MFCs are promising in further practical applications with low cost macrocycles catalysts.
\end{abstract}

Keywords : Oxygen reduction, Nutrient solution, Fe-TMPP, Non-Pt, Microbial fuel cells

\section{Introduction}

A microbial fuel cell (MFC) is an electrochemical system which employs exoelectrogenic biofilm as a biocatalyst for electricity generation (Fig. 1). ${ }^{1-8)}$ Exoelectrogenic microorganisms in biofilms oxidize various biodegradable substrates generating electrons and protons. The electrons

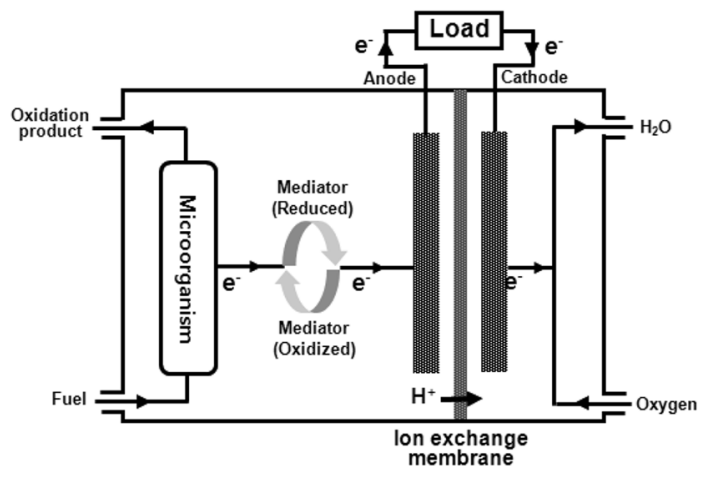

Fig. 1. A schematic diagram of a microbial fuel cell.

*E-mail: ohsangeun@kangwon.ac.kr(Sang-Eun Oh) kwpark@ssu.ac.kr(Kyung-Won Park) are transferred to the cathode electrode through an external circuit while the protons diffuse through the solution to the cathode, where electrons combine with protons and oxygen to form water.

The exploration of non-noble metal catalysts, alternatives to $\mathrm{Pt}$, has been of intensive interest in chemical fuel cells. Jasinski et al. reported for the first time ORR catalysts with macrocyclic structure containing nitrogen-metal coordination. Several non-noble transition metals such as Co, $\mathrm{Fe}$, and $\mathrm{Mn}$ have been studied in the form of iron(III) phthalocyanine $(\mathrm{FePc})$ and Cobalt tetramethoxyphenylporphyrin (CoTMPP) for oxygen reduction reaction (ORR).-14) The pyrolyzed transition metal- $\mathrm{N}_{4}$ complexes such as $\mathrm{Fe}-$ or Co-based macrocycles in an inert atmosphere have been reported to demonstrate the catalytic activity and stability for the oxygen reduction reaction at $\left.80^{\circ} \mathrm{C} . .^{15,16}\right)$ However, the subsequent works using several carbonsupported transition metal- $\mathrm{N}_{4}$ macrocycles showed high activation losses in PEMFCs at low pHs. ${ }^{17,18)}$ The chemical fuel cell systems operate under much different conditions of $\mathrm{pH}$ (highly acid conditions) and temperature $\left(70-90^{\circ} \mathrm{C}\right.$ ) compared to neural $\mathrm{pH}$ and temperature $\left(25-30^{\circ} \mathrm{C}\right)$ of MFCs. Carbon supported Fe-tetramethoxyphenylporphyrin 
(TMPP) [19] as the cathode have not been tested in a neutral cathode medium in a MFC.

Herein, we have studied an oxygen reduction reaction of carbon-supported Fe-tetramethoxyphenylporphyrin (Fe-TMPP/C) and compared with ORR of carbon and Pt-coated carbon. The Fe-TMPP/C catalyst was characterized using X-ray photoelectron spectroscopy (XPS), X-ray diffraction (XRD), scanning electron microscopy (SEM) and transmission electron microscopy (TEM). The electrochemical ORR characteristics of Fe-TMPP, Pt-coated carbon, and carbon were compared using voltammetry. Finally, these cathode catalysts were implemented into a MFC reactor and were also compared for cell potential and power output.

\section{Experimental}

To prepare the carbon-supported Fe-TMPP (FeTMPP/C) catalyst, iron(III) acetatylacetonate $(0.03 \mathrm{~g}$, Aldrich) and 5,10,15,20-tetrakis(4-methoxyphenyl)$21 \mathrm{H}, 23 \mathrm{H}$-porphyrin ( $\mathrm{H}_{2} \mathrm{TMPP}, 0.1 \mathrm{~g}$, Aldrich) were dissolved in acetic acid (99.7\%, Aldrich) solution for $1 \mathrm{~h}$. After completely dissolving, carbon powder (Vulcan $\mathrm{XC}-72 \mathrm{R}$ ) was added slowly into the solution to form a homogeneous blended solution by adsorbing the Fe-TMPP on carbon. After an adequate stirring, the solution was completely evaporated and then dried at $60^{\circ} \mathrm{C}$ overnight. The obtained powder was placed in a quartz boat and heat-treated at $700^{\circ} \mathrm{C}$ for $3 \mathrm{~h}$ in a horizontal quartz furnace under $\mathrm{N}_{2}$ atmosphere. For comparison with the Fe-TMPP/ C $\left(0.5 \mathrm{mg} / \mathrm{cm}^{2} ; 20 \mathrm{wt} \%\right.$ Fe-TMPP $)$ the Pt-coated carbon (E-Tek, USA) coated with a Pt-catalyst $\left(0.5 \mathrm{mg} / \mathrm{cm}^{2}\right.$; $10 \mathrm{wt} \% \mathrm{Pt}$ ) on one side and carbon (E-Tek, USA) were used as the cathodes.

The catalysts were characterized by transmission electron microscopy (TEM) using a Philips CM20T/STEM Electron Microscope system at $200 \mathrm{kV}$. The TEM sample was prepared by placing a drop of the catalyst suspension with ethanol on a carbon-coated copper grid. Scanning electron microscopy (SEM, JSM-6700F) and energy dispersive X-ray (EDX, EX-23000BUB) analyzer were used to identify the Fe-TMPP in the catalyst. X-ray photoelectron spectrometry (XPS, Thermo Scientific) study was carried out with the $\mathrm{Al} \mathrm{K} \mathrm{K}_{\alpha} \mathrm{X}$-ray source of $1486.6 \mathrm{eV}$ at the chamber pressure below $5 \times 10^{-9} \mathrm{~Pa}$.

To characterize oxygen reduction reaction of the catalysts, cyclic voltammetry $(\mathrm{CV})$ and linear sweep voltam- metry (LSV) were obtained using a potentiostat $(\mathrm{CH}$ Instruments Inc. $700 \mathrm{C}$ Series) in a three-electrode electrochemical cell with a RRDE-3A rotator $(\mathrm{CH}$ Instruments Inc.). The catalyst onto a glassy carbon disk (disk diameter of $0.4 \mathrm{~mm}$ )-platinum ring (ring width of 0.7-0.5 mm) electrode, $\mathrm{Pt}$ wire, and $\mathrm{Ag} / \mathrm{AgCl}$ were used as a working, counter, and reference electrode, respectively. The catalyst ink was prepared by ultrasonically blending the mixture of catalyst powder $(10 \mathrm{mg}), 57.2 \mu \mathrm{L}$ Nafion solution $(0.5 \mathrm{wt} \%$ Ionomer, Aldrich), $57.2 \mu \mathrm{L}$ isopropanol, and $114.4 \mu \mathrm{L}$ deionized water for $10 \mathrm{~min}$. The ink $(1 \mu \mathrm{L})$ was dropped onto the glassy carbon disk and dried at $50^{\circ} \mathrm{C}$ for $10 \mathrm{~min}$. The total catalyst loading is $347.8 \mu \mathrm{g} \mathrm{cm}^{-2}$. The voltammetry of the catalysts was performed between 0 and $1.2 \mathrm{~V}$ in oxygen-saturated nutrient solution with a scan rate of $5 \mathrm{mV} \mathrm{s}^{-1}$. The nutrient solution $(\mathrm{pH}=7.0)$ consists of $4.33 \mathrm{~g} \mathrm{~L}^{-1} \mathrm{Na}_{2} \mathrm{HPO}_{4}, 2.69 \mathrm{~g} \mathrm{~L}^{-1} \mathrm{NaH}_{2} \mathrm{PO}_{4} \cdot \mathrm{H}_{2} \mathrm{O}$, $0.31 \mathrm{~g} \mathrm{~L}^{-1} \mathrm{NH}_{4} \mathrm{Cl}, 0.13 \mathrm{gL}^{-1} \mathrm{KCl}$, and $12.5 \mathrm{~mL}$ vitamin solution in de-ionized water. ${ }^{8)}$ For the rotating ring disk electrode (RRDE) measurement, the ring potential was fixed at $1.2 \mathrm{~V}$ versus RHE with a scan rate of $5 \mathrm{mV} \mathrm{s}^{-1}$ and a rotating speed of $1,600 \mathrm{rpm}$. All of the experiments were performed at room temperature and ambient pressure.

Two-chamber MFCs with an aqueous-cathode were used in order to assess the performance of different cathode catalysts (Fe-TMPP/C, Pt/C, and C). The two bottles $(250 \mathrm{~mL})$ were connected with a glass tube (inner diameter: $3.5 \mathrm{~cm}^{2}$ ) with a proton exchange membrane (NafionTM 117, Dupont Co., Delaware, USA) held by a clamp in the middle of the tube as previously described. ${ }^{20)}$ The distance between the electrodes was approximately $16 \mathrm{~cm}$. All the two-chambered MFCs were operated at $30^{\circ} \mathrm{C}$. The anode and cathode compartments were filled with the nutrient solution $(250-\mathrm{mL})$ and the anode chamber was inoculated with anaerobic sludge from the Wastewater Treatment Plant in Chuncheon, Korea $(10 \mathrm{~mL})$. Acetate $(2 \mathrm{mM})$ was used as the electron donor. The anode chamber was sparged with nitrogen gas for 3-5 minutes and sealed with a rubber stopper and cap. The anode $(2.5 \times$ $4.0 \mathrm{~cm})$ and Pt-coated cathode were connected with a resistor $(1 \mathrm{k} \Omega)$ and the current produced was calculated by measuring the voltage across a resistor every $30 \mathrm{~min}$ utes using a multimeter. Once the voltage increased and stabilized at around $300 \mathrm{mV}$, the Pt cathode was replaced with the prepared different cathode materials. Currentvoltage response and power density curve were analyzed by the IviumStat electrochemical analyzer (IVIUM 
Technology, The Netherlands). The current was increased from 0 to $0.4 \mathrm{~mA}$ in series. At each level of current, the voltage response was recorded after stabilization in 600$1200 \mathrm{sec}$. The reference electrode was placed to cathode as close as possible to reduce overpotential.

\section{Results and discussion}

A SEM image of Fe-TMPP supported by carbon (FeTMPP/C) for oxygen reduction reaction was shown in Fig. 2(a). The Fe-TMPP/C seems to be homogeneously mesoporous structure for electrochemical reduction in nutrient solution facilitating oxygen diffusion. The FeTMPP/C seems to be the carbon particles mixed with TMPP exchanged by iron metal (Fig. 2(b)). In other
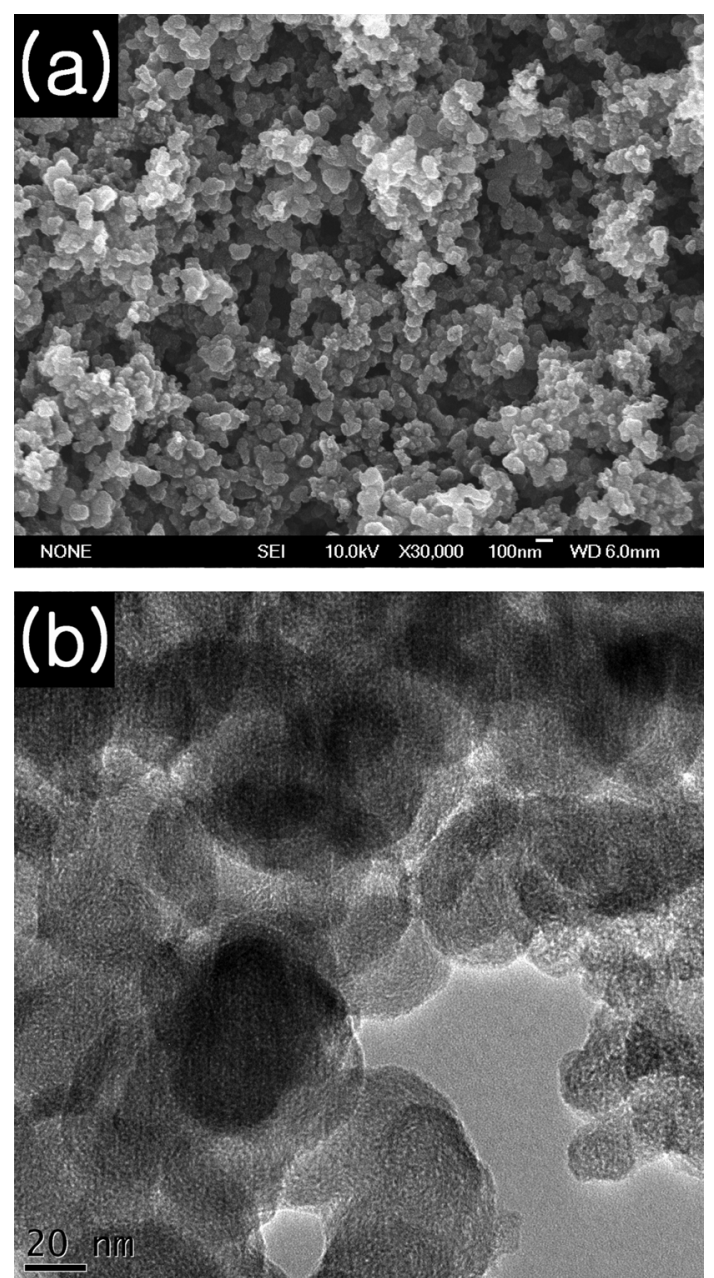

Fig. 2. (a) SEM and (b) TEM images of Fe-TMPP/C. words, the Fe-TMPP is well dispersed on the carbon particles without any precipitates such as iron oxides or nitrides. As shown in Fig. 3(a), C 1s spectrum consists of five peaks at 283.83, 284.78, 285.88, 286.78, 288.18, and $291.18 \mathrm{eV}$ corresponding to carbide, C-C, C-N, C-O (ethers), C-O(carboxyls), and $\mathrm{C}-\mathrm{O}$ (carbonates), respectively. In $\mathrm{N}$ 1s spectrum of Fig. 3(b), the pyridinic-N is assigned to the component at $398.8 \mathrm{eV}$ and quaternary$\mathrm{N}$ is presented for the peak at $401.08 \mathrm{eV}$.

Fig. 4(a) shows the LSVs recorded on a glassy carbon disk electrode coated with the catalysts in an oxygensaturated nutrient solution with a scan rate of $5 \mathrm{mV} \mathrm{s}^{-1}$ at $25^{\circ} \mathrm{C}$. The onset potentials for the $\mathrm{C}, \mathrm{Fe}-\mathrm{TMPP} / \mathrm{C}, \mathrm{Pt} / \mathrm{C}$ are $0.52,0.94$, and $1.01 \mathrm{~V}$, respectively, where more positive potential indicates higher catalytic activity. Thus, this means that the Fe-TMPP/C shows much improved ORR activity in comparison with the $\mathrm{C}$ and relatively comparable to the $\mathrm{Pt} / \mathrm{C}$. The reduction current densities at $0 \mathrm{~V}$
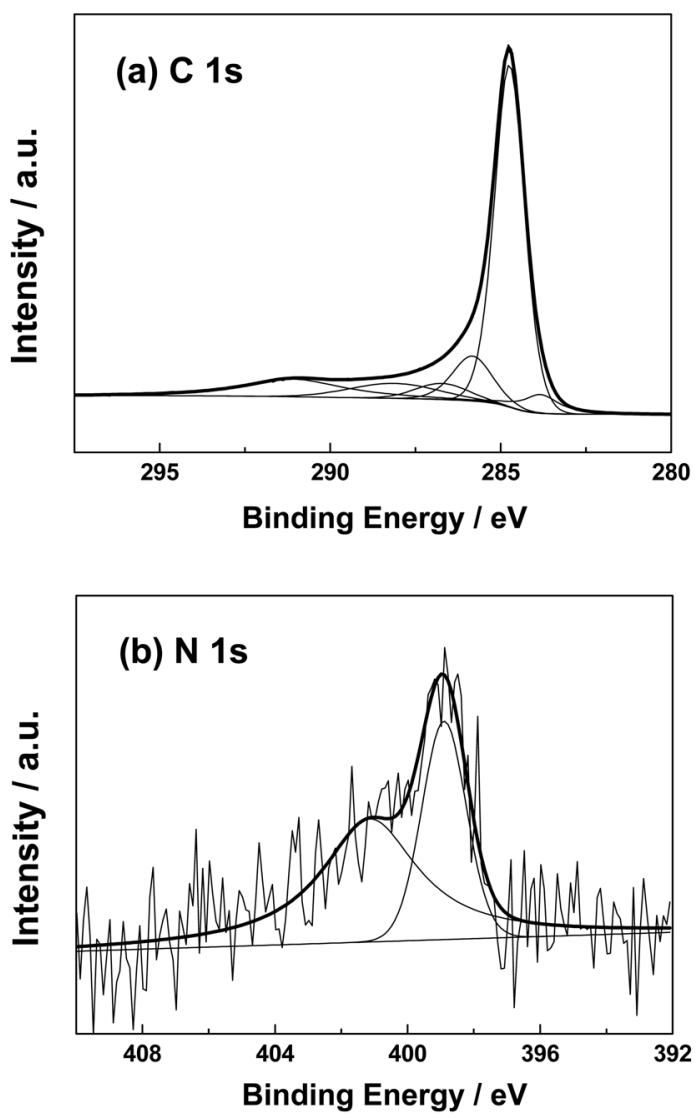

Fig. 3. XPS spectra of (a) $\mathrm{C} 1 \mathrm{~s}$ and (b) $\mathrm{N} 1 \mathrm{~s}$ of Fe-TMPP/C. 

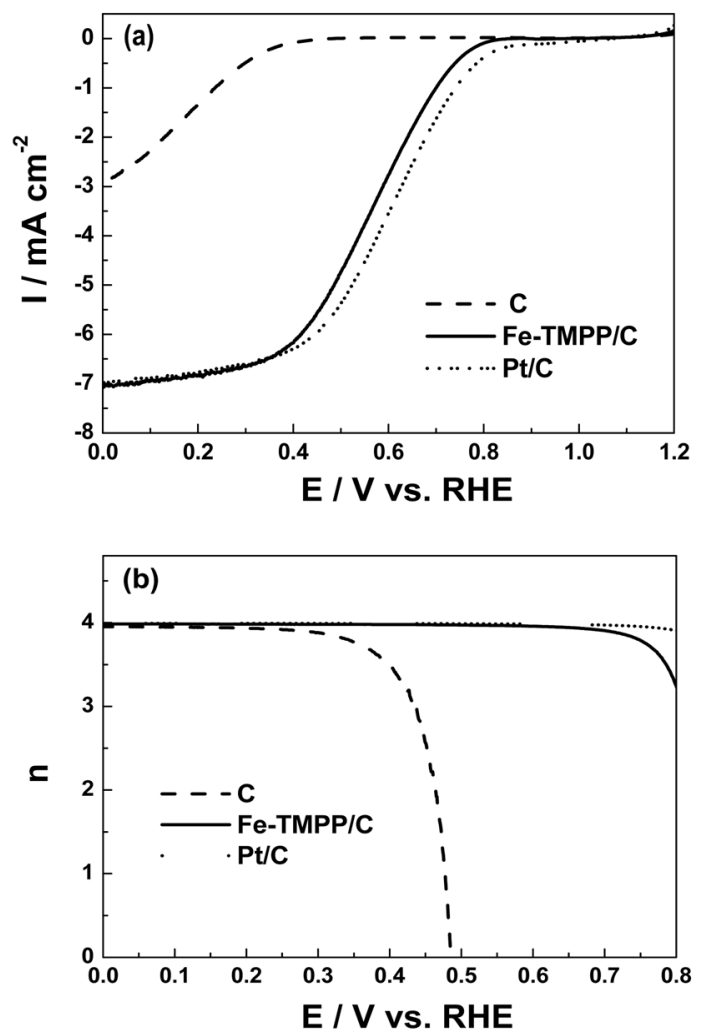

Fig. 4. (a) Current density versus potential and (b) electron number versus potential for oxygen reduction reaction of the catalysts in oxygen-saturated nutrient solution with a scan rate of $5 \mathrm{mV} \mathrm{s}^{-1}$ and an electrode rotation rate of $1,600 \mathrm{rpm}$.

for the Fe-TMPP/C and $\mathrm{Pt} / \mathrm{C}$ are 2.75 and $2.50 \mathrm{~mA} \mathrm{~cm}^{-2}$, respectively. Fig. 4(b) shows the plots of electron number (n) for ORR versus electrode potential of the $\mathrm{C}, \mathrm{Fe}-$ TMPP/C and Pt/C at an elecrode rotation rate of $1,600 \mathrm{rpm}$ in oxygen saturated nutrient solution with a scan rate of $5 \mathrm{mV} \mathrm{s}^{-1}$. For a quantitative evaluation for ORR mechanism, the electron number $(n)$ onto the glassy carbon diskplatinum ring electrode can be calculated by the following equation:

$$
n=4 I_{D}\left(I_{D}+\left(I_{R} N^{-1}\right)\right)^{-1}
$$

where $I_{D}$ is the faradic current at the disk electrode, $I_{R}$ is the faradic current at the ring electrode, and $N=0.43$ is the RRDE collection efficiency. As shown in the Fig. 4(b), it can be seen that the ORR catalyzed by the $\mathrm{C}$ proceeds mainly through a two-electron oxygen reduction pathway at the low polarization range, and then
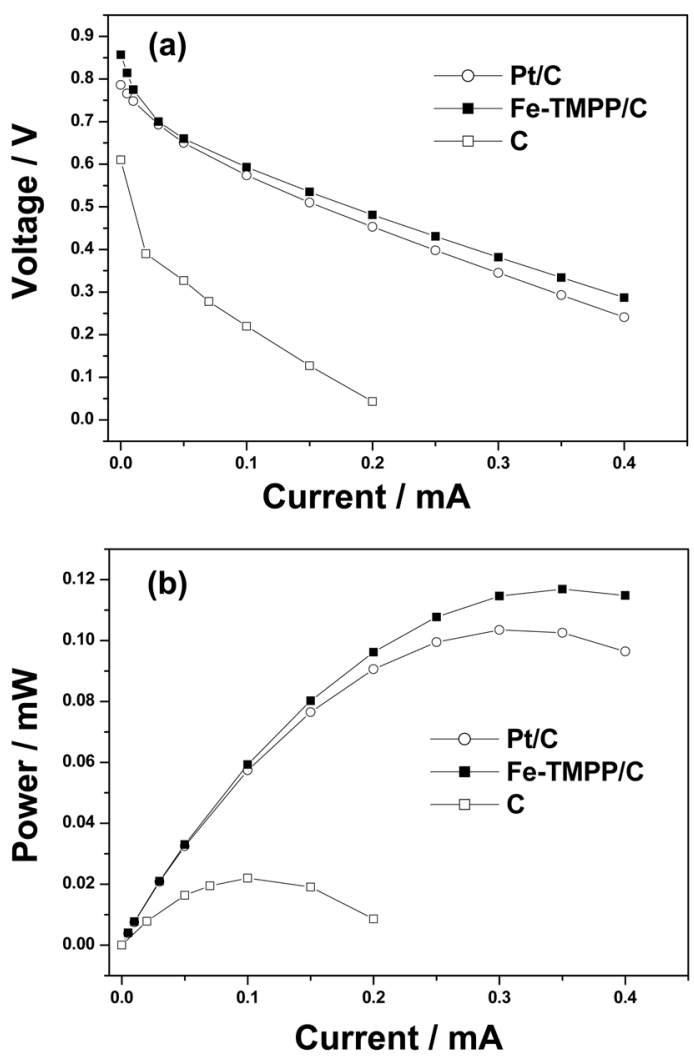

Fig. 5. Cell performances of the two-chambered MFC using different cathode catalysts with saturated dissolved oxygen.

the electron number increases when electrode potential is scanned to a more negative direction where the produced hydrogen peroxide can be further reduced. In contrast, the ORR catalyzed by the Fe-TMPP/C has a more stable mechanism with a constant nearly four electron number for ORR between 0 and $0.7 \mathrm{~V}$. Similar to that of the $\mathrm{Pt} / \mathrm{C}$, the electron number for ORR of the Fe-TMPP/C is about four even at higher potential than $+0.1 \mathrm{~V}$.

The current-potential curves of the different catalysts were shown in Fig. 5(a). The open circuit voltages (OCVs) for the $\mathrm{C}, \mathrm{Pt} / \mathrm{C}$, and $\mathrm{Fe}-\mathrm{TMPP} / \mathrm{C}$ are $0.61,0.80$, and $0.86 \mathrm{~V}$, reapectively. More positive $\mathrm{OCV}$ indicates much improved catalytic activity, meaning that the Fe-TMPP/C shows an excellent ORR activity in comparison with the $\mathrm{C}$ and $\mathrm{Pt} / \mathrm{C}$. At $0.6 \mathrm{~V}$, where an activation polarization regime dominates, reduction current densities are $0.001 \mathrm{~mA}$ (C), $0.081 \mathrm{~mA}(\mathrm{Pt} / \mathrm{C})$ and $0.095 \mathrm{~mA}$ (Fe-TMPP/C). Moreover, at $0.4 \mathrm{~V}$, where an Ohmic polarization regime dominates, the reduction current density for the $\mathrm{Pt} / \mathrm{C}$ 
(0.25 mA) is comparable to that of Fe-TMPP/C (0.29 mA).

The Fe-TMPP/C produced a higher maximum power density than $\mathrm{Pt} / \mathrm{C}$, which is 120 and $600 \%$ higher than that of the $\mathrm{Pt} / \mathrm{C}$ and the $\mathrm{C}$, respectively. The maximum power of the Fe-TMPP/C is $0.12 \mathrm{~mW}$ as compared with $0.10 \mathrm{~mW}$ of the Pt/C, and $0.02 \mathrm{~mW}$ of the $\mathrm{C}$ (Fig. $5(\mathrm{~b})$ ). The excellent performance of the Fe-TMPP/C may be due to a superior electrocatalytic activity, low electrical resistance for current collection, and the unique pore characteristics of the electrode, which favors the diffusion of oxygen and the removal of the by-product $\mathrm{H}_{2} \mathrm{O}$ might result in the improved performance. In particular, the decreased cell performance using $\mathrm{Pt} / \mathrm{C}$ cathode may be due to the crossover products such as formic acid, acetic acid from the anode. Detailed studies on the origins of the excellent performance of the Fe-TMPP/C will be reported in the future. From the results of the practical electrochemical cell, we conclude that the Fe-TMPP/C is an excellent candidate for the electrodes of microbial fuel cells.

\section{Conclusions}

The catalyst structure of heat-treated macrocyclic complex with nitrogen provided much improved oxygen reduction reaction for the MFC. The Fe-TMPP/C produced both higher reduction current density and maximum power density than those of the $\mathrm{Pt} / \mathrm{C}$ and $\mathrm{C}$. The excellent performance of the Fe-TMPP/C might be due to an improved ORR activity of the catalyst. Thus, the catalyst can reduce Pt loading and replace expensive noble catalysts in MFCs.

\section{Acknowledgments}

This work was supported by Korea Research Foundation Grant funded by the Korean Government (MOEHRD, Basic Research Promotion Fund) (KRF-2008-314-F00014) and Manpower Development Program for Energy \& Resources supported by the Ministry of Knowledge and Economy, Republic of Korea (20104010100610).

\section{References}

1. B. E. Logan and N.J. Hoboken, "Microbial fuel cells", Wiley-Interscience. xii, New York (2008).

2. B. E. Logan, 'Exoelectrogenic bacteria that power microbial fuel cells' Nat. Rev. Micro., 7, 375 (2009).
3. D. R. Lovely, J. D. Wall, C. S. Harwood, and A. L. Demain, "Electricity production with electricigens", ASM Press. Washington D.C. (2008).

4. K. Rabaey, S. T. Read, P. Clauwaert, S. Freguia, P. L. Bond, L. L. Blackall, and J. Keller, 'Cathodic oxygen reduction catalyzed by bacteria in microbial fuel cells' ISME J., $\mathbf{2}$, 519 (2008).

5. K. Rabaey and W. Verstraete, 'Microbial fuel cells: novel biotechnology for energy generation' Trends Biotechnol., 23, 291(2005).

6. J. R. Kim, S. Cheng, S. E. Oh, and B. E. Logan, 'Power generation using different cation, anion, and ultrafiltration membranes in microbial fuel cells' Environ. Sci. Technol., 41, 1004 (2007).

7. S. E. Oh, J. R. Kim, J. H. Joo, and B. E. Logan, 'Effects of applied voltages and dissolved oxygen on sustained power generation by microbial fuel cells' Water Sci. Technol., 60, 1311 (2009).

8. S. E. Oh, B. Min, and B. E. Logan, Environ. 'Cathode performance as a factor in electricity generation in microbial fuel cells' Sci. Technol., 38, 4900 (2004).

9. S. Cheng, H. Liu, and B. E. Logan, Environ. 'Power densities using different cathode catalysts (Pt and CoTMPP) and polymer binders (Nafion and PTFE) in single microbial fuel cells' Sci. Technol., 40, 364 (2006).

10. S. You, Q. Zhao, J. Zhang, J. Jiang, and S. Zhao, 'A microbial fuel cell using permanganate as the cathodic electron acceptor' J. Power Sources, 162, 1409 (2006).

11. F. Zhao, F. Harnisch, U. Schroder, F. Scholz, P. Bogdanoff, and I. Herrmann, 'Application of pyrolysed iron(II) phthalocyanine and CoTMPP based oxygen reduction catalysts as cathode materials in microbial fuel cells' Electrochem. Comm., 7, 1405 (2005).

12. L. Zhang, J. J. Zhang, D. P. Wilkinson, and H. J. Wang, 'Progress in preparation of non-noble electrocatalysts for PEM fuel cell reactions' J. Power Sources, 156, 171 (2006).

13. E. H.Yu, S. Cheng, K. Scott, and B. Logan 'Microbial fuel cell performance with non-Pt cathode catalysts' J. Power Sources, 171, 275 (2007).

14. R. Jasinski, 'A New Fuel Cell Cathode Catalyst' Nature, 201, 1212 (1964).

15. T. Schilling and M. Bron, 'Oxygen reduction at Fe-Nmodified carbon nanotubes in acidic electrolyte' Electrochim. Acta, 53, 5379 (2008).

16. R. Bashyam and P. Zelenay, 'A class of non-precious metal composite catalysts for fuel cells' Nature, 443, 63 (2006).

17. B. Wang, 'Recent development of non-platinum catalysts for oxygen reduction reaction' J. Power Sources, 152, 1 (2005).

18. C. W. B. Bezerra, L. Zhang, K. Lee, H. Liu, A. L. B. Marques, E. P. Marques, H. Wang, and J. Zhang, 'A review of $\mathrm{Fe}-\mathrm{N} / \mathrm{C}$ and $\mathrm{Co}-\mathrm{N} / \mathrm{C}$ catalysts for the oxygen reduction reaction' Electrochim. Acta, 53, 4937 (2008).

19. K. Lee, L. Zhang, H. Lui, R. Hui, Z. Shi, and J. J. Zhang, 'Oxygen reduction reaction (ORR) catalyzed by carbon- 
supported cobalt polypyrrole (Co-PPy/C) electrocatalysts' Electrochim. Acta, 54, 4704 (2009).

20. S.-E. Oh and B.E. Logan, 'Proton exchange membrane and electrode surface areas as factors that affect power generation in microbial fuel cells' Appl Microbiol. Biotechnol., 70, 162 (2006).
21. F. Harnisch, S. Wirth and U. Schroder, 'Effects of substrate and metabolite crossover on the cathodic oxygen reduction reaction in microbial fuel cells: Platinum vs. iron(II) phthalocyanine based electrodes' Electrochem. Comm., 11, 2253 (2009). 